\title{
Variability of UV Irradiance in Europe
}

Gunther Seckmeyer*1, Darius Pissulla ${ }^{1}$, Merle Glandorf ${ }^{1}$, Diamantino Henriques ${ }^{2}$, Bjorn Johnsen ${ }^{3}$, Ann Webb ${ }^{4}$, Anna-Maria Siani ${ }^{5}$, Alkis Bais ${ }^{6}$, Berit Kjeldstad ${ }^{7}$, Colette Brogniez ${ }^{8}$, Jacqueline Lenoble ${ }^{9}$, Brian Gardiner $^{10}$, Peter Kirsch ${ }^{10}$, Tapani Koskela ${ }^{11}$, Jussi Kaurola ${ }^{11}$, Beate UhImann ${ }^{12}$, Harry Slaper ${ }^{13}$, Peter den Outer ${ }^{13}$, Michal Janouch ${ }^{14}$, Peter Werle ${ }^{15}$, Julian Gröbner ${ }^{16}$, Bernhard Mayer ${ }^{17}$, Alain de la Casiniere ${ }^{18}$, Stana Simic ${ }^{19}$ and Fernanda Carvalho ${ }^{2}$

${ }^{1}$ Institute of Meteorology and Climatology, Leibniz University of Hannover, Hannover, Germany

${ }^{2}$ Instituto de Meteorologia, Lisbon, Portugal

${ }^{3}$ Norwegian Radiation Protection Authority, Østerås, Norway

${ }^{4}$ School of Earth Atmospheric and Environmental Sciences, University of Manchester, Manchester, UK

${ }^{5}$ Universita di Roma La Sapienza, Rome, Italy

${ }^{6}$ Laboratory of Atmospheric Physics, Aristotle University of Thessaloniki, Thessaloniki, Greece

${ }^{7}$ Department of Physics, Norwegian University of Science and Technology, Trondheim, Norway

${ }^{8}$ Laboratoire d'Optique Atmosphérique, Univ des Science et Technologies de Lille, Lille, France

${ }^{9}$ Interactions Rayonnement Solaire et Atmosphère, Université Joseph Fourier, Grenoble, France

${ }^{10}$ British Antarctic Survey, Cambridge, UK

${ }^{11}$ Finnish Meteorological Institute, Helsinki, Finland

${ }^{12}$ Beiersdorf, Hamburg, Germany

${ }^{13}$ RIVM, Bilthoven, The Netherlands

${ }^{14}$ Solar and Ozone Observatory of the Czech Hydrometeorological Institute, Hradec Kralove, Czech Republic

${ }^{15}$ Research Center Karlsruhe, Karlsruhe, Germany

${ }^{16}$ Physikalisch-Meteorologisches Observatorium Davos, World Radiation Center, Davos, Switzerland

${ }^{17}$ DLR, Oberpfaffenhofen, Germany

${ }^{18}$ Equipe IRSA, Université Joseph Fourier, Grenoble, France

${ }^{19}$ University of Natural Resources and Applied Life Sciences, Institute of Meteorology, Vienna, Austria

Received 19 April 2007, accepted 28 August 2007, DOI: 10.1111/j.1751-1097.2007.00216.x

\section{ABSTRACT}

The diurnal and annual variability of solar UV radiation in Europe is described for different latitudes, seasons and different biologic weighting functions. For the description of this variability under cloudless skies the widely used onedimensional version of the radiative transfer model UVSPEC is used. We reconfirm that the major factor influencing the diurnal and annual variability of UV irradiance is solar elevation. While ozone is a strong absorber of $\mathrm{UV}$ radiation its effect is relatively constant when compared with the temporal variability of clouds. We show the significant role that clouds play in modifying the UV climate by analyzing erythemal irradiance measurements from 28 stations in Europe in summer. On average, the daily erythemal dose under cloudless skies varies between $2.2 \mathrm{~kJ} \mathrm{~m}^{-2}$ at $70^{\circ} \mathrm{N}$ and $5.2 \mathrm{~kJ} \mathrm{~m}^{-2}$ at $35^{\circ} \mathrm{N}$, whereas these values are reduced to $1.5-4.5 \mathrm{~kJ} \mathrm{~m}^{-2}$ if clouds are included. Thus clouds significantly reduce the monthly $U V$ irradiation, with the smallest reductions, on average, at lower latitudes, which corresponds to the fact that it is often cloudless in the Mediterranean area in summer.

*Corresponding author email: seckmeyer@muk.uni-hannover.de (Gunther Seckmeyer)

(c) 2007 The Authors. Journal Compilation. The American Society of Photobiology 0031-8655/08

\section{INTRODUCTION}

Solar radiation plays a vital role for life on earth. It provides the energy for the photosynthesis of plants, upon which all higher organisms ultimately depend. The UV radiation at the short-wave end of the solar spectrum cannot be detected by the human eye, though it is visible to some insects. UV radiation causes pigmentation of the skin in humans and also in the leaves of some plants. This is a protective mechanism but in western cultures a tan is often wrongly associated with good health. An important positive effect of UV exposure is the synthesis of vitamin D. However, solar UV radiation is also known to have adverse effects on the biosphere including terrestrial and aquatic ecosystems as well as public health. For humans, exposure to UV radiation from the sun is associated with skin cancer, accelerated ageing of the skin, cataract and other eye diseases. It may also affect people's ability to resist infectious diseases, and compromise the effectiveness of vaccination programs. Many plants react to increased UV radiation with reduced growth or diminished photosynthetic activity. Phytoplankton, which forms the first link in the maritime food chain, may be damaged as well. The deterioration of materials exposed to solar radiation, and attempts to protect against it, have significant economic consequences.

Ozone absorbs radiation strongly in the UV, and the presence of ozone and oxygen in the stratosphere results in the absorption of all solar radiation below about $290 \mathrm{~nm}$. Thus 
virtually no UV-C radiation $(200-280 \mathrm{~nm}$ ) reaches the troposphere or the earth's surface. Solar UV-B radiation (280$315 \mathrm{~nm}$ ) is significantly absorbed by atmospheric ozone, whereas only a small fraction $(<3 \%)$ of UV-A radiation $(315-400 \mathrm{~nm})$ is absorbed by ozone. As a consequence of the observed decline in stratospheric ozone concentration it has been found that UV levels have increased in high- and midlatitudes (1). It is not yet clear if and when ozone will fully recover, so aside from the inherent risk from solar UV radiation, life on earth may be confronted with a further or sustained rise in UV.

Accurate measurement of solar spectral UV irradiance has historically been a difficult task and was first undertaken by Bener at the physical meteorological observatory Davos at the end of the 1950s $(2,3)$. Bener set such high standards that it took more than 20 years before new analysis of the variability of spectral UV irradiance - this time including the effect of clouds - was performed (4). The fact that irradiance varies by many orders of magnitude over a relatively short wavelength range $(290-315 \mathrm{~nm})$ requires that useful instruments have a wide dynamic range, with low stray light levels and a low uncertainty in general $(5,6)$. Also the long-term stability of UV instruments and their absolute calibration standards are still difficult to maintain. Consequently, good quality routine spectral measurements did not start until the late 1980s and these longer records are few in number. Assessment of the present knowledge of UV irradiance and its changes can be found in Kerr et al. (7) and Bais et al. (1).

Clouds are an important factor for the actual UV irradiance. They can attenuate UV irradiance by more than $99 \%$ in extreme cases. If averaged over the whole day clouds have only a moderate influence on UV spectra (8), whereas instantaneous values can be influenced quite dramatically by clouds. It is known that clouds cannot be considered as simple gray filters (9). The present knowledge of the effects of clouds has been summarized in WMO/UNEP ozone assessments (7) and Bais et al. (1). Clouds have more influence on surface UV irradiance than any other atmospheric variable. However, the effect of clouds on UV irradiance is difficult to quantify. The effect of clouds on UV is understood in principle, but in practice the necessary parameters used to calculate local cloud effects are rarely available and even if they were, the complexities of cloud geometry need to be specified in sufficient detail and require the use of 3D model calculations (1).

Under overcast conditions, clouds decrease the irradiance measured at the surface $(10,11)$. However, enhancements of up to $25 \%$ can occur under broken cloud conditions by reflected radiation from the cloud sides $(12-14)$, or if there are reflections from cloud decks below high altitude observation sites such as Mauna Loa Observatory (15). Even for large cloud fractions, the reduction in irradiance can be small if the clouds do not obscure the direct beam. Thus, one of the most important parameters is whether or not the sun is obscured $(16,17)$. When a histogram of cloud transmission is plotted as a function of cloud amount a bimodal distribution typically results (18-20) with a lower peak resulting from conditions when clouds obscure the sun, and a higher peak corresponding to conditions where clouds do not block the sun. As the sun may be unobscured even for large cloud fractions, or may be obscured even for small cloud fractions, the quantification of cloud effects can become problematic $(21,22)$. There are also complications when the scattering of radiation by clouds enhances effects such as absorption by ozone $(23,24)$ or scattering by aerosols (25) within the cloud.

The presence of scattered or broken clouds poses difficulties for comparisons between ground-based measurements and satellite estimates of surface UV irradiance. In this situation direct solar radiation is either obscured or not obscured by a cloud at the ground-based measurement site, whereas the satellite measures an average cloud amount over the area of its footprint. There have been a number of studies showing that the derivation of UV irradiance from satellite instruments is problematic because they use backscattered UV radiation for the retrieval. Detailed studies have demonstrated that these satellite-based methods seriously underestimate UV irradiances in the northern hemisphere, where satellite-derived UV irradiance can sometimes exceed groundbased measurements by more than $40 \%$. It has been suggested $(20,26)$ that the discrepancy arises because the satellite instrument does not effectively probe the boundary layer, where extinctions by aerosol and clouds can be important. Another approach is the derivation of satellitederived UV irradiance by using geostationary satellites in combination with polar orbiting satellites (27-29). The deviation of these satellite products from ground-based measurements is about $10 \%$ smaller, but the major difficulty of the limited probing of the boundary layer is hard to overcome.

Sliney and Wengraitis (30) described the effects of UV-B radiation depending on the season and region for humans. In summer, the time for erythema (sunburn) is estimated to be less than $20 \mathrm{~min}$ in mid-latitudes for sensitive skin. Sliney and Wengraitis (30) further described that the challenge for public health authorities is to provide simple, understandable messages for sensitive individuals to limit excessive exposure at appropriate times of the day during spring and summer months and yet not to take needless precautions or limit exposure during fall and winter months at mid- or polar latitudes. The appropriate exposure for beneficial effects (e.g. vitamin-D synthesis) may not be achievable in midlatitudes during winter, but is readily achieved in summer months. Consequently the messages to the public should differentiate between summer and winter exposure, the time of the day and the geographic latitude.

\section{MATERIALS AND METHODS}

The spectral irradiance in the UV is strongly wavelength dependent and the UV spectrum changes with time. The biologic weighting functions generally have a pronounced dependence on wavelength. The presentation of this complexity can be simplified by using weighted irradiance instead of the spectral irradiance to represent biologically effective UV. The most common weighting functions are erythema, as defined by the Commission Internationale de l'Eclairage (CIE) (31) and the DNA damaging weighting function (32). Following the same concept UVA and UVB integrals can be considered as UVA weighting function defined as the integral from 315 to $400 \mathrm{~nm}$ and the UVB weighting function defined by the integral of the spectral irradiance from 280 to $315 \mathrm{~nm}$. The persistent pigment darkening (PPD) (33) function is often used to describe the direct pigmentation of the skin. The diurnal and annual variability of the PPD function and the UV-A are nearly identical, therefore UV-A can be used as a good proxy for the PPD function in this context. Although not used within this document, there are many more weighting functions, which vary greatly with wavelength, e.g. CIE (34). 
It should be emphasized that biologic weighting functions are associated with considerable uncertainties. This is mainly due to the difficulty of accurately measuring the spectral behavior of the biologic effect under consideration. The concept of weighting functions only works if the effects of different wavelengths are additive. This is by no means guaranteed and there are strong indications that some effects operate synergistically. For plant reactions it is known that the UV effects are strongly influenced by visible radiation, which is used to repair damage caused by shortwave UV radiation (35). For these reasons weighted irradiances should only be considered as indicators for the effects that they describe.

The first goal of this document is a description of the diurnal, annual and latitudinal variations of weighted UV irradiance for cloudless skies. The purpose is to describe some basic features of UV variability instead of explaining the full complexity of all parameters influencing UV. This is achieved by employing an internationally wellaccepted model package libRadtran (36). The central program is the tool UVSPEC whose radiative transfer solvers are based on the algorithms described by Stamnes et al. (37) and it solves the radiative transfer equation for one dimension, which is sufficient for cloudless skies and homogenous cloud layers. The pseudo-spherical solver of UVSPEC, which is used throughout this study, has been extensively compared with measurements (7); the deviation between modeled and measured UV irradiance is between $5 \%$ and $10 \%$ for moderate and known aerosol optical depth (AOD), for known ozone column and for solar zenith angles (SZA) less than $80^{\circ}$ and wavelengths greater than $300 \mathrm{~nm}$ and cloudless skies $(7,32)$. The deviation between measured and modeled UV irradiance is within the combined measurement and modeling uncertainty (due to the uncertainties in measured input parameters) $(5,38)$. For all calculations an ozone column of $300 \mathrm{DU}$, a ground albedo of 0.1 and a visibility of $30 \mathrm{~km}$ have been assumed. According to the model implementation the visibility of $30 \mathrm{~km}$ corresponds to an AOD of 0.3 for a wavelength of $344 \mathrm{~nm}$. Although in reality the albedo is wavelength dependent with spatial and temporal dependencies, its value is assumed to be independent of wavelength, location and time to simplify this study. These values are typical for mid and high latitudes in summer. As described in Mayer and Killing (36) all other parameters were taken from the US Standard atmosphere.

Due to the importance of clouds another goal was to investigate to what extent the latitudinal dependencies can also be found in monthly averages at selected stations for all sky conditions. As there is insufficient information about clouds to completely model their influence, all-sky measurements were compared with the cloudless sky model to determine the cloud modification at selected sites. In this analysis, the data from the European UV database (39) (http:// www.muk.uni-hannover.de/ seckmeyer/EDUCE/ or http://uvdb.fmi. fi/uvdb/index.html) were used. The database was set up by the EU-funded projects Scientific UV data management (SUVDAMA), European Database for UV Climatology and Evaluation (EDUCE) and Stratosphere-Climate Links With Emphasis on the Upper Troposphere and the Lower Stratosphere (SCOUT-O3).

Ideally, continuous measurements recorded over decades with more or less identical instruments would be used for such a study. However, such measurements do not exist. The instrument systems are diverse, the longest time series are only about 15 years in duration and there are gaps in the data at all stations. To overcome these problems a strict site selection criterion was relaxed in favor of increasingly usable data sets. The resulting selection criteria were: A monthly average was constructed if there were at least 20 days of measurements with less than a combined $3 \mathrm{~h}$ of data gaps within a month. Only spectra measured in the months May, June, July and August were taken into account. This selection was made to avoid situations with high snow albedo (which would complicate the interpretation of the data) (40). All available data were taken from a period covering 7 years (starting in 1997 and ending 2003). There are more data before 1997, but the common starting date was chosen to avoid the possibility of different temporal trends in the data. To overcome the disparity in instrument type and performance, and the complexity of representing spectral data, a common data product, the erythemally weighted irradiation was used in this part of the study. Some of the instruments do not cover the full wavelength range to $400 \mathrm{~nm}$ that is necessary to calculate the erythemal weighted irradiance directly; therefore it is necessary to supplement the missing data by extrapolation using modeled data.
Such extrapolation methods have been developed and applied $(41,42)$ in the past mainly for instruments measuring up to $365 \mathrm{~nm}$. To be able to include data with a wavelength range up to $325 \mathrm{~nm}$ and for the handling of the large amount of spectra with reasonable computing time, a new look-up table technique was developed for this study using the UVSPEC model. In a final step all monthly mean values were averaged and a standard deviation of each average was calculated, thus providing the summertime (May-August) monthly mean all-sky erythemally weighted UV for each site. The station names and their coordinates are given in Table 1, a map with the stations included is shown in Fig. 1.

For all selected days (and months) the monthly mean cloudless sky data were calculated by UVSPEC with ozone values taken from TOMS satellite data. Another input is the altitude of the station, which is especially relevant for the two altitude stations Zugspitze and Sonnblick.

\section{RESULTS}

\section{Diurnal variations}

Figure 2 shows the diurnal variation of the UV irradiance integrated from 280 to $315 \mathrm{~nm}$, in the following called UV-B irradiance, for $21 \mathrm{June}$ at $53^{\circ} \mathrm{N}$. The values of UV-B for a latitude of $\sim 53^{\circ}$ are characteristic of Dublin (Ireland), Liverpool (UK), Hamburg or Berlin (Germany) or Warsaw (Poland). In addition the integrated UV-A (315-400 nm), DNA and erythemally weighted irradiance are shown for comparison. Normalization factors are $174 \mathrm{~mW} \mathrm{~m}^{-2}$ for erythemally, $105 \mathrm{~mW} \mathrm{~m}^{-2}$ for DNA, $1309 \mathrm{~mW} \mathrm{~m}^{-2}$ for UV-B and $45776 \mathrm{~mW} \mathrm{~m}^{-2}$ for UV-A weighted irradiance. The maximum solar elevation is $60.6^{\circ}$ on that day.

Looking at a given time and location the SZA is the dominant factor that determines the spectral detail as well as absolute solar UV irradiance. As a consequence the UV spectrum depends on location, on the time of the day and on the day within a year. By comparing the diurnal variation of UV-A and UV-B irradiance it can be seen that the diurnal variation of the UV-A irradiance is broader around the noon maximum than the UV-B irradiance, which can be explained by the longer path length for solar radiation in the morning and the evening in combination with the absorption of UV-B radiation by stratospheric ozone and the greater scattering at shorter wavelengths. The two biologic weighting functions illustrated are those of erythema and DNA damage. The DNA weighting function is the most sensitive to shortwave UV, giving DNA the narrowest diurnal distribution, as shown in Fig. 2. The erythemal diurnal radiation is broader partly because this action spectrum extends into the UVA.

The ratio of UV-B irradiance to UV-A irradiance, which is shown in Fig. 2, has a maximum at noon time. The $\mathrm{UV}-\mathrm{B} / \mathrm{UV}-\mathrm{A}$ ratio is about $3 \%$ around noon and decreases below $1 \%$ near sunrise and sunset. The absolute irradiance (both UV-A and UV-B) is very small when the sun is below the horizon. In addition the ratio becomes very sensitive to the actual atmospheric conditions. Therefore these values are suppressed for times with the sun below the horizon.

\section{Annual variations}

This section describes annual variations of the weighted UV irradiance for noon (12:00 local time) at $53^{\circ} \mathrm{N}$. All model assumptions in this section are the same as in the previous section. 
Table 1. List of the measuring stations in Europe with their geographic coordinates, altitudes, and measured (all sky) and modeled (cloudless sky) values of monthly mean of erythemally weighted daily dose.

\begin{tabular}{|c|c|c|c|c|c|}
\hline Station & Latitude $\left({ }^{\circ} \mathrm{N}\right)$ & Longitude $\left({ }^{\circ} \mathrm{E}\right)$ & Altitude (m) & Measured $\left(\mathrm{J} \mathrm{m}^{-2}\right)$ & Modeled $\left(\mathrm{J} \mathrm{m}^{-2}\right)$ \\
\hline Funchal (Portugal) & 32.6 & -16.9 & 58 & 4361 & 5465 \\
\hline Lampedusa (Italy) & 35.5 & 12.6 & 50 & 4566 & 5210 \\
\hline Lisbon (Portugal) & 38.8 & -9.2 & 100 & 4503 & 4952 \\
\hline Thessaloniki (Greece) & 40.6 & 23 & 80 & 3601 & 4855 \\
\hline Rome (Italy) & 41.9 & 12.5 & 60 & 3668 & 4776 \\
\hline Briançon (France) & 44.9 & 6.7 & 1310 & 3913 & 4957 \\
\hline Ispra (Italy) & 45.8 & 8.6 & 214 & 3014 & 4368 \\
\hline Sonnblick (Austria) & 47.1 & 13 & 3105 & 3570 & 4859 \\
\hline Zugspitze (Germany) & 47.4 & 11 & 2965 & 2733 & 4859 \\
\hline Garmisch-Partenkirchen (Germany) & 47.5 & 11.1 & 730 & 2671 & 4294 \\
\hline Hohenpeissenberg (Germany) & 47.8 & 11 & 980 & 2933 & 4341 \\
\hline Neuherberg (Germany) & 48.2 & 11.6 & 493 & 3146 & 4350 \\
\hline Großenzersdorf (Austria) & 48.2 & 16.6 & 156 & 2750 & 4350 \\
\hline Offenbach (Germany) & 50 & 8.7 & 124 & 2662 & 4132 \\
\hline Hradec Kralove (Czech Republic) & 50.2 & 15.8 & 285 & 2740 & 4007 \\
\hline Villeneuve d'Ascq (France) & 50.6 & 3.1 & 70 & 2528 & 3881 \\
\hline Uccle (Belgium) & 50.8 & 4.4 & 105 & 2431 & 3837 \\
\hline Reading (UK) & 51.5 & 0.9 & 66 & 2489 & 3865 \\
\hline Belsk (Poland) & 51.8 & 20.8 & 180 & 2434 & 3724 \\
\hline Bilthoven (The Netherlands) & 52.1 & 5.2 & 9 & 2312 & 3629 \\
\hline De Bilt (The Netherlands) & 52.1 & 5.2 & 17 & 2328 & 3619 \\
\hline Lindenberg (Germany) & 52.2 & 14.1 & 121 & 2164 & 3267 \\
\hline Potsdam (Germany) & 52.4 & 13.1 & 107 & 2585 & 3614 \\
\hline Oesteraas (Norway) & 59.9 & 10.8 & 50 & 2313 & 3148 \\
\hline Jokioinen (Finland) & 60.8 & 23.5 & 107 & 2141 & 2940 \\
\hline Trondheim (Norway) & 63.4 & 10.5 & 20 & 1693 & 2784 \\
\hline Sodankylä (Finland) & 67.4 & 26.6 & 179 & 1750 & 2372 \\
\hline Andøya (Norway) & 69.3 & 16 & 380 & 1395 & 2419 \\
\hline
\end{tabular}

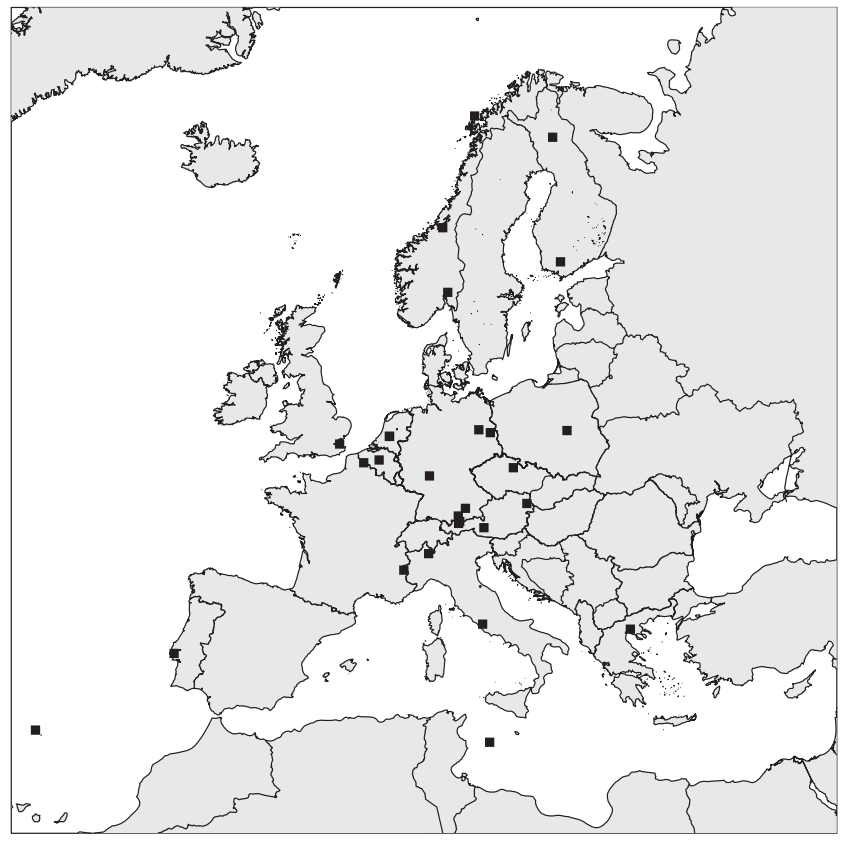

Figure 1. Location of stations with measurements of spectral irradiance fulfilling the selection criteria.

Figure 3 shows the annual variation of the UV-B, UV-A, DNA and erythemally weighted irradiance for noon time. The curves shown here are symmetric around the summer maximum on 21 June. The sun-earth distance varies over the year, with a maximum in summer and a minimum in winter. This variation, which is $6.4 \%$ at most, is contained in Fig. 3. The

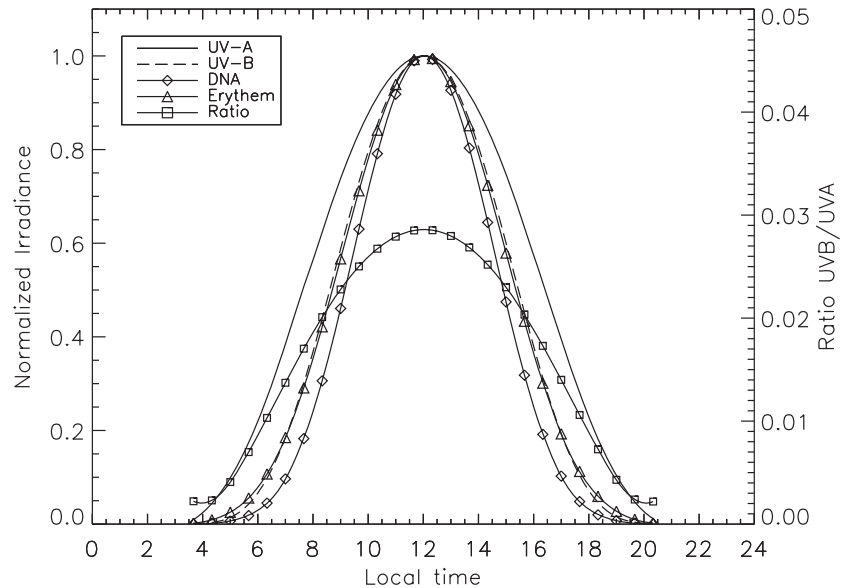

Figure 2. Modeled diurnal variation of normalized integrated weighted irradiance (left axis) and the ratio of UV-B to UV-A irradiance (right axis) for $21 \mathrm{June}$ at $53^{\circ} \mathrm{N}$. Normalization factors are given in the main text. Compared to UV-A the UV-B, erythemal and DNA weighted irradiance distributions are narrower and more confined to the period around noon. The ratio UV-B/UV-A becomes very small in the early morning and the evening.

variation of the ozone column is included in Fig. 3. In reality this will lead to a curve that is not symmetric around 21 June, because the spring ozone columns are higher than the summer values. Therefore the actual UV-B-maximum is slightly shifted from the summer solstice towards late summer. However, the dominating factors determining the UV-B irradiance are usually the solar elevation and cloudiness and the annual ozone cycle has a small influence compared with these factors. By comparing the two curves it can be recognized that the 


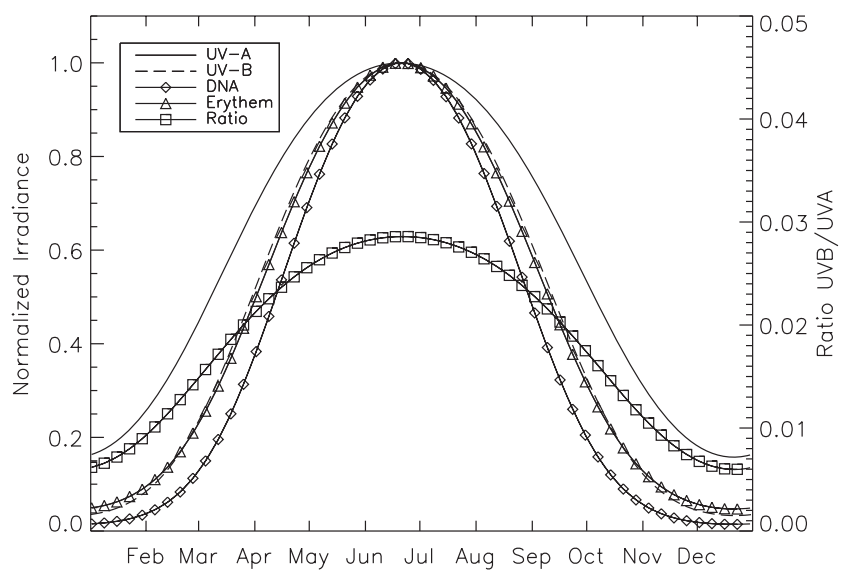

Figure 3. Annual variation of the integrated and normalized weighted irradiance (left axis) and the ratio of UV-B to UV-A irradiance (right axis) at $53^{\circ} \mathrm{N}$. Normalization factors are given in the main text. Compared to UV-A, the UV-B, erythemal and DNA weighted irradiance distribution are far more confined around the maximum value on 21 June. The ratio UV-B/UV-A becomes very small in winter.

annual variation of the UV-A irradiance is broader around the summer maximum than the UV-B irradiance. This behavior is more pronounced in the annual variation of the DNA weighted irradiance (solid line with diamonds) which weights the short wavelengths more heavily than the longer wavelengths.

As a consequence the ratio of UV-B irradiance to UV-A irradiance, which is also shown in Fig. 3 (solid line with squares which refers to the right $y$-axis), has a maximum on 21 June. The UV-B/UV-A ratio is more than $3 \%$ on 21 June and decreases to about $1 \%$ in winter.

\section{UV irradiance at different latitudes}

Diurnal variations. In previous sections the UV irradiance weighted with different weighting functions was shown for one site only and a latitude of $53^{\circ} \mathrm{N}$ was chosen as an example for densely populated areas.

Figure 4 shows the diurnal variation erythemally weighted irradiance and the ratios of UV-B to UV-A on 21 June at $35^{\circ}$, $53^{\circ}$ and $70^{\circ}$. The local time is the time when the minimum SZA occurs at 1200 , which is independent of the longitude. In this figure the changes with latitude are shown, calculated using the same atmospheric conditions as before. On 21 June at $35^{\circ}$ the erythemally weighted irradiance day is shorter but with more intense values around noon compared to the erythemally weighted irradiance at higher latitudes. The ratio of UV-B irradiance to UV-A irradiance, which is shown in Fig. 4, has a maximum for all latitudes at noon. The UV-B/UV-A ratio at $35^{\circ} \mathrm{N}$ is more than $3 \%$ around noon and declines to $0 \%$ at sunrise and sunset. The absolute irradiance (both UV-A and UV-B) is insignificant, compared to noon, when the sun is below the horizon. In addition the ratio is very sensitive to the actual atmospheric conditions. Therefore values from $35^{\circ}$ and $53^{\circ} \mathrm{N}$ are suppressed for times when the sun is below the horizon. The UV-B/UV-A ratio at $70^{\circ} \mathrm{N}$ is nearly $2 \%$ around noon and below $0.5 \%$ at midnight (when the sun is still above the horizon). SZA controls the ratio, especially in the fixed atmosphere model, and latitude controls SZA. Thus there is a

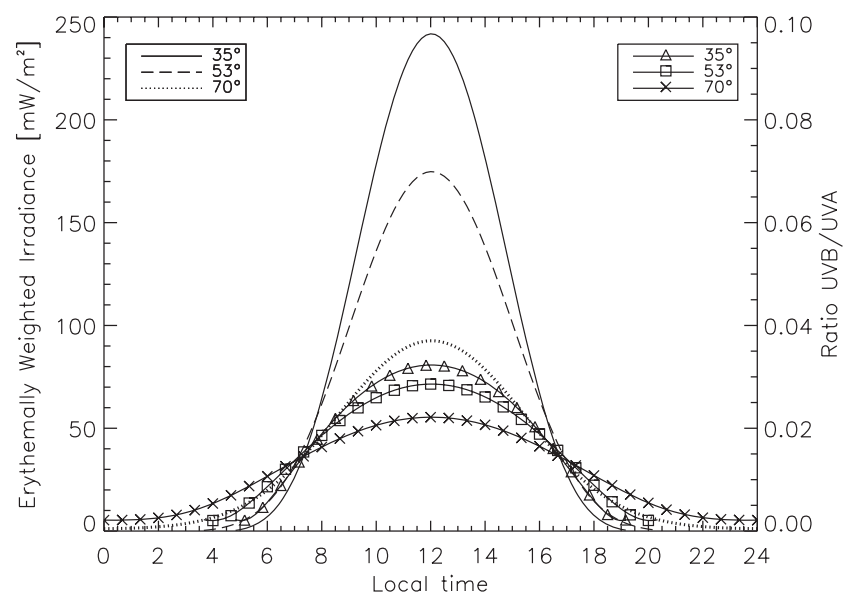

Figure 4. Diurnal variation of the erythemally weighted irradiance for 21 June at $35^{\circ} \mathrm{N}$ (solid line), $53^{\circ} \mathrm{N}$ (dashed line) and $70^{\circ} \mathrm{N}$ (dotted line) with the corresponding ratios of UV-B to UV-A irradiance (right axis) for the same latitudes. See upper right legend for the symbols on the curves. The ratio UV-B/UV-A becomes very small for latitudes below $65^{\circ} \mathrm{N}$ as the sun is below the horizon at nighttime.

time (about 0730 and 1730 local time) when the ratios are similar at all latitudes because SZA is the same at all latitudes. Between these times (day) the SZA is smaller and ratio higher at low latitudes. Outside these times (night) the extended day length at high latitudes results in a definite UV-B/UV-A ratio, while at low latitudes it is dark.

Annual variations. Figure 5 shows the annual variation of the erythemally weighted irradiance for noon at $35^{\circ}, 53^{\circ}$ and $70^{\circ}$. For $70^{\circ}$ the erythemally weighted irradiance is close to zero for several months because the sun is below the horizon in winter. In winter the erythemally weighted irradiance is still considerable at $35^{\circ} \mathrm{N}$ compared to the higher latitudes where there is no danger of erythema by sun exposure in winter.

The ratio of UV-B to UV-A irradiance, which is shown in Fig. 5, has a maximum on 21 June. The UV-B/UV-A ratio for $35^{\circ}$ is higher than $3 \%$ in summer and about $1.5 \%$ during

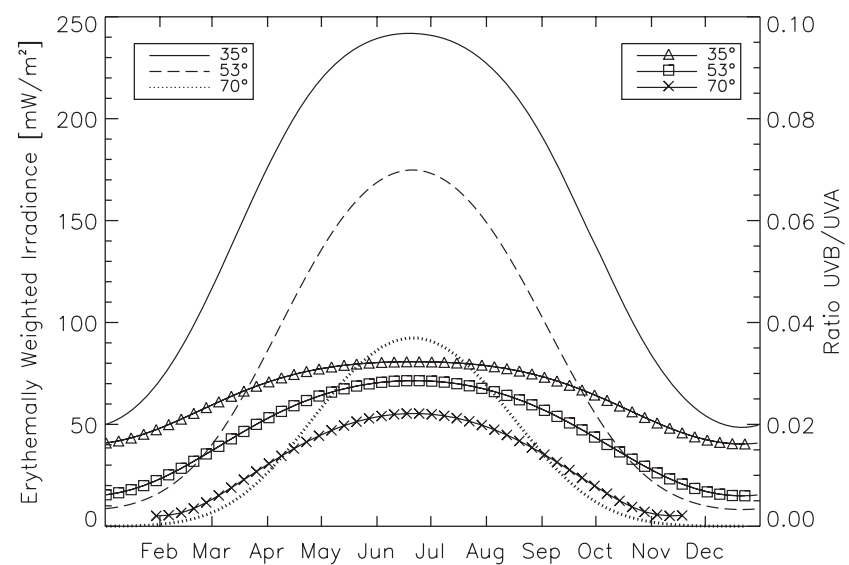

Figure 5. Annual variation of the erythemally weighted irradiance for noon at $35^{\circ} \mathrm{N}$ (solid line), $53^{\circ} \mathrm{N}$ (dashed line) and $70^{\circ} \mathrm{N}$ (dotted line) with ratios of UV-B to UV-A irradiance (right axis) for the same latitudes. See upper right legend for the symbols on the curves. The ratio UV-B/UV-A becomes very small for latitudes below $65^{\circ} \mathrm{N}$ as the sun is below the horizon at nighttime. 


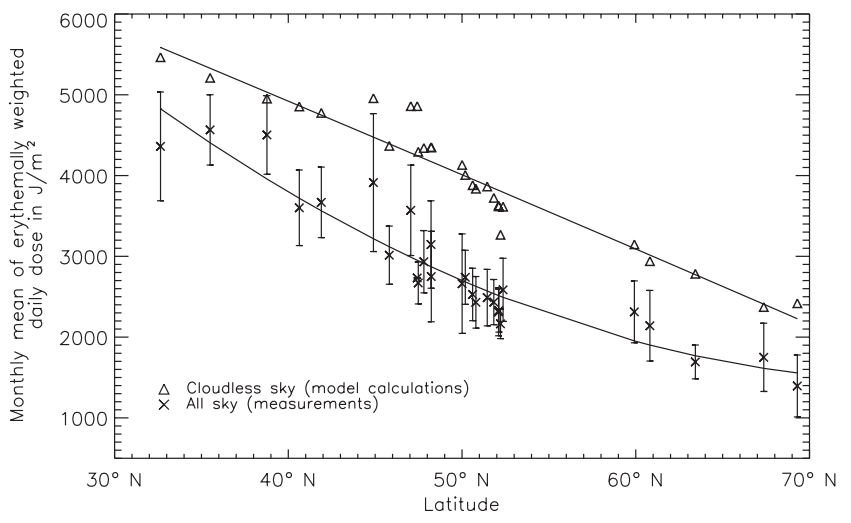

Figure 6. Comparison between cloudless sky calculations and actual measurements of monthly mean erythemally weighted irradiance. The two curves are spline fitted lines. The error bars denote the year-to-year variability (one sigma standard deviation) in the measured monthly mean, no measurement uncertainties are included.

winter, thus showing much less annual variation compared to higher latitudes. The ratio for $53^{\circ}$ has a maximum below $3 \%$ in summer and has a minimum of $0.5 \%$ in winter. The $\mathrm{UV}-\mathrm{B} / \mathrm{UV}-\mathrm{A}$ ratio for $70^{\circ}$ is about $2 \%$ in summer and is nearly zero in winter.

\section{UV irradiance under cloudy skies}

The previous sections have shown SZA control on both spectral shape and the absolute UV irradiance, illustrated for both annual and diurnal cycles, at different latitudes for cloudless, constant atmosphere conditions. However, for most regions in Europe a cloudless sky is not the norm, thus a realistic assessment of UV must also consider cloud.

The cloud effect is illustrated by a comparison between cloudless sky calculations and actual measurements of monthly mean erythemal daily dose (Fig. 6).

For the cloudless sky, values of measured ozone columns from TOMS satellite on the days matched to the UV measurement selections were used in the model calculations. Thus, there is a site (latitude)-dependent atmospheric variable included in the clear sky calculations, which was not the case in the earlier sections, and thus the symbols do not lie exactly on the fitted curve. The UV irradiance for all sky conditions is, on average, decreased by cloud, but not equally at all sites. While the SZA remains the dominant influence on UV irradiance, its effect is modified by cloudiness and to a lesser extent variations in ozone across the European region. While the average cloud effect serves to reduce UV radiation it should be emphasized that clouds can also significantly enhance UV irradiance above the cloudless sky values in specific cases.

\section{DISCUSSION}

It should be noted that the measured data have a number of limitations.

- There are several data gaps, which are different at the different stations. Therefore the monthly means could not always be included.
- The uncertainty of the erythemal irradiance is between $5 \%$ and $6 \%$ at best (5); for specific cases it could be higher despite the great efforts with quality control and quality assurance at the database (42). The absolute measurement of UV radiation still belongs to the most delicate meteorological measurements.

- The extrapolation of data that is necessary for a large number of stations causes additional uncertainties, especially in those cases where no measurement data are available beyond $325 \mathrm{~nm}$.

- The calculations for Figs. 2-4 are based on the assumption of constant AOD, which certainly does not reflect reality. For clear skies the impact of aerosols is estimated between $0 \%$ and $20 \%(1)$. In reality it is very difficult to distinguish between aerosol and cloud effects. This is not a side effect as both parameters are usually present simultaneously.

For these reasons accurate UV measurements and attributions of influencing factors are still a challenging task, but the conclusions presented here are not based on measurements from single instruments. It reflects the great achievements gained over the recent decade with such measurements and it does not aim at a quantitative identification of all factors that control the variability of UV irradiance in Europe, at least not for all circumstances.

Despite these limitations of the individual data sets, it is clear that on average clouds significantly reduce erythemal UV irradiation. This investigation into the natural variability of solar UV radiation has shown that the largest variability is the result of changes in SZA on a diurnal and annual basis. A higher SZA implies a longer path through the atmosphere than for a lower SZA and a corresponding stronger attenuation of solar radiation by the atmosphere. We have shown through model calculations of clear sky UV radiation that this attenuation is strongly wavelength dependent, with much larger absorption at shorter wavelengths due to the strong wavelength-dependent ozone absorption coefficients in the UV wavelength region (Huggins bands), and also increased Rayleigh scattering as wavelength increases. This SZA-dependent effect is also responsible for the latitudinal gradient of solar UV radiation seen with model calculations and substantiated by the results from measurements obtained from $31 \mathrm{UV}$ monitoring sites in Europe. Finally, we have shown that on average clouds are a significant contributor to the solar UV variability (see error bars in Fig. 6). On average, the daily erythemal dose under cloudless skies varies between $2.2 \mathrm{~kJ} \mathrm{~m}^{-2}$ at $70^{\circ} \mathrm{N}$ and $5.2 \mathrm{~kJ} \mathrm{~m}^{-2}$ at $35^{\circ} \mathrm{N}$, whereas these values are reduced to $1.5-4.5 \mathrm{~kJ} \mathrm{~m}^{-2}$ if clouds are included. Southern latitudes are not as much influenced by clouds, which corresponds to the fact that it is often cloudless in the summer months in the Mediterranean. Therefore, the data from the European UV database show that clouds have a significant impact on actual UV levels. The UV database may also be used to further improve the validation of satellite-derived UV irradiance, which will be the only viable way to gain information on the UV irradiance with higher spatial coverage than available from a ground-based spectroradiometric network. 


\section{REFERENCES}

1. Bais, A. F., D. Lubin, A. Arola, G. Bernhard, M. Blumthaler, N. Chubarova, C. Erlick, H. P. Gies, N. Krotkov, K. Lantz, B. Mayer, R. L. McKenzie, R. D. Piacentini, G. Seckmeyer, J. R. Slusser and C. S. Zerefos (2007) Surface ultraviolet radiation: Past, present, and future, Chapter 7. In Scientific Assessment of Ozone Depletion: 2006. Global Ozone Research and Monitoring Project. Report no. 50, pp. 7.1-7.54. World Meteorological Organization, Geneva.

2. Bener, P. (1960) Investigation on the Spectral Intensity of Ultraviolet Sky and Sun + Sky Radiation under Different Conditions of Cloudless Weather at $1590 \mathrm{~m}$ a.s.l. Technical summary report no. I, contract AF 61(052)-54. Physikalisch-Meteorologisches Observatorium Davos, Davos-Dorf, Switzerland.

3. Bener, P. (1967) A New Spectrophotometer for Measuring Ultraviolet Sky Brightness and direct Solar Radiation. Final scientific report, contract AF 61(052)-618. Physikalisch-Meteorologisches Observatorium Davos, Davos-Dorf, Switzerland.

4. Seckmeyer, G. (1989) Spectral measurements of the variability of global UV-radiation. Meteorol. Rundsch. 41, 180-183.

5. Bernhard, G. and G. Seckmeyer (1999) Uncertainty of measurements of spectral solar UV irradiance. J. Geophys. Res. Atmos. 104, 14321-14345.

6. Seckmeyer, G., A. F. Bais, G. Bernhard, M. Blumthaler, P. Eriksen, R. L. McKenzie, C. Roy and M. Miyauchi (2001) Instruments to measure solar ultraviolet radiation, part 1: Spectral instruments. WMO-GAW 126, 9-12.

7. Kerr, J. B., G. Seckmeyer, A. F. Bais, G. Bernhard, M. Blumthaler, S. B. Diaz, N. Krotkov, D. Lubin, R. L. McKenzie, A. A. Sabziparvar and J. Verdebout (2003) Surface ultraviolet radiation: Past and future, Chapter 5. In WMO/UNEP Assessment on Ozone Depletion, 2002. Global Ozone Research and Monitoring Project Report no. 47, pp. 5.1-5.46. World Meteorological Organization, Geneva.

8. Den Outer, P. N., H. Slaper, A. Bais, U. Feister, M. Janouch, W. Josefsson, J. Kaurola and T. Koskela (2007) UV climatology from quality controlled ground-based spectral UV-measurements. In Remote Sensing of Clouds and the Atmosphere, XI, Vol. 6362 (Edited by J. R. Slusser, K. Schaefer and A. Comeron), pp. 636214-636224. Proceedings of SPIE. International Society for Optical Engineering, Bellingham.

9. Kylling, A., A. Albold and G. Seckmeyer (1997) Transmittance of a cloud is wavelength-dependent in the UV-range: Physical interpretation. Geophys. Res. Lett. 24, 397-400.

10. Josefsson, W. and T. Landelius (2000) Effect of clouds on UV irradiance: As estimated from cloud amount, cloud type, precipitation, global radiation and sunshine duration. J. Geophys. Res, 105, 4927-4935.

11. Renaud, A., J. Staehelin, C. Fröhlich, R. Philipona and A. Heimo (2000) Influence of snow and clouds on erythemal UV radiation: Analysis of Swiss measurements and comparison with models. J. Geophys. Res. 105, 4961-4969.

12. Estupiñán, J. G., S. Raman, G. H. Crescenti, J. J. Streicher and W.F. Barnard (1996) Effects of clouds and haze on UV-B radiation. J. Geophys. Res. 101, 16807-16816.

13. Sabburg, J. and J. Wong (2000) The effect of clouds on enhancing UVB irradiance at the earth's surface: A one year study. Geophys. Res. Lett., 27, 3337-3340.

14. Weihs, P., A. R. Webb, S. J. Hutchinson and G. W. Middleton (2000) Measurements of the diffuse UV sky irradiance during broken cloud conditions. J. Geophys. Res. 105, 4937-4944.

15. McKenzie, R. L., P. V. Johnston, D. Smale, B. Bodhaine and S. Madronich (2001) Altitude effects on UV spectral irradiance deduced from measurements at Lauder, New Zealand and at Mauna Loa Observatory, Hawaii. J. Geophys. Res, 106, 22845 22860.

16. Grant, R. H. and G. M. Heisler (2000) Estimation of ultraviolet irradiance under variable cloud conditions. J. Appl. Meteorol. 39, 904-916.

17. Schwander, H., P. Koepke, A. Kaifel and G. Seckmeyer (2002) Modifications of spectral UV irradiance by clouds. J. Geophys. Res, 107, AAC7-1-AAC7-12.
18. Seckmeyer, G., B. Mayer, G. Bernhard, R. Erb, A. Albold, H. Jäger and W. R. Stockwell (1997) New maximum UV irradiance levels observed in Central Europe. Atmos. Environ. 31, 29712976.

19. McKenzie, R. L., K. J. Paulin, G. E. Bodeker, J. B. Liley and A. P. Sturman (1998) Cloud cover measured by satellite and from the ground: Relationship to UV radiation at the surface. Int. J. Remote Sens. 19, 2969-2985.

20. McKenzie, R. L., G. Seckmeyer, A. F. Bais, J. B. Kerr and S. Madronich (2001) Satellite-retrievals of erythemal UV dose compared with ground-based measurements at Northern and Southern mid-latitude. J. Geophys. Res. 106, 24051-24062.

21. Udelhofen, P. M., P. Gies and C. Roy (1999) Surface UV radiation over Australia, 1979-1992: Effects of ozone and cloud cover changes on variations of UV radiation. J. Geophys. Res. 104 19135-19159.

22. Matthijsen, J., H. Slaper, A. G. M. Reinen and G. J. M. Velders (2000) Reduction of solar UV by clouds: A remote sensing approach compared with ground-based measurements. J. Geophys. Res, 105 5069-5080.

23. Fioletov, V. E., J. B. Kerr and D. I. Wardle (1997) The relationship between total ozone and spectral UV irradiance from Brewer observations and its use for derivation of total ozone from UV measurements. Geophys. Res. Lett. 24, 2997-3000.

24. Mayer, B., A. Kylling, S. Madronich and G. Seckmeyer (1998) Enhanced absorption of UV radiation due to multiple scattering in clouds: Experimental evidence and theoretical explanation. J. Geophys. Res. 103, 31241-31254.

25. Erlick, C., J. E. Frederick, V. K. Saxena and B. N. Wenny (1998) Atmospheric transmission in the ultraviolet and visible: Aerosols in cloudy atmospheres. J. Geophys. Res. 103, 31541-31556.

26. Kazantzidis, A., A. F. Bais, J. Gröbner, J. Herman, S. Kazadzis, N. Krotkov, E. Kyro, P. den Auter, K. Garane, P. Görts, K. Lakkala, C. Meleti, H. Slaper, R. Tax and T. Turunen (2006) Comparison of satellite-derived UV irradiances with groundbased measurements at four European stations. J. Geophys. Res. 111, D13207.

27. Verdebout, J. (2004a) A European satellite-derived UV climatology available for impact studies. Radiat. Prot. Dosim. 111(4), 407411 .

28. Verdebout, J. (2004b) A satellite-derived UV radiation climatology over Europe to support impact studies. Arct. Antarct. Alp. Res. 36(3), 357-363.

29. Wuttke, S., J. Verdebout and G. Seckmeyer (2003) An improved algorithm for satellite-derived UV radiation. Photochem. Photobiol. 77(1), 52-57.

30. Sliney, D. H and S. Wengraitis (2006) Is a differentiated advice by season and region necessary? Prog. Biophys. Mol. Biol. 92(1), 150 160.

31. McKinlay, A. F. and B. L. Diffey (1987) A reference action spectrum for ultraviolet induced erythema in human skin. CIE $J$. 6, $17-22$.

32. Bernhard, G., B. Mayer, G. Seckmeyer and A. Moise (1997) Measurements of spectral solar UV irradiance in tropical Australia. J. Geophys. Res. 102, 8719-8730.

33. Moyal, D., A. Chardon and N. Kollias (2000) Determination of UVA protection factors using the persistent pigment darkening (PPD) as the end point. Photodermatol. Photoimmunol. Photomed. 16, 245-249.

34. CIE (2003) Spectral weighting of solar ultraviolet radiation. CIE Document 151, pp. 1-30. CIE, Central Bureau, Vienna. Available at www.cie.co.at/cie/.

35. Sinha, R. P. and D.-P. Haeder (2002) UV induced DNA damage and repair: A review. Photochem. Photobiol. Sci. 1, 225-236.

36. Mayer, B. and A. Kylling (2005) Technical note: The libRadtran software package for radiative transfer calculations - description and examples of use. Atmos. Chem. Phys. 5, 1855-1877.

37. Stamnes, K., S. C. Tsay, W. J. Wiscombe and K. Jayaweera (1988) Numerically-stable algorithm for discrete-ordinate radiative transfer in multiple scattering and emitting layered media. Appl. Opt. 27, 2502-2509.

38. Cordero, R. R., L. DaSilva, D. Pissulla and G. Seckmeyer (2007) Uncertainty evaluation of the spectral UV irradiance evaluated by 
using the UVSPEC Radiative Transfer Model. Optic. Comm. 276(1), 44-53.

39. Seckmeyer, G. (2000) Coordinated ultraviolet radiation measurements. Radiat. Protect. Dosim. 91, 99-103.

40. Wuttke, S., G. Seckmeyer and G. Koenig-Langlo (2006) Measurements of spectral snow albedo at Neumayer, Antarctica. Ann. Geophys. 24, 7-21.

41. Bais, A. F., A. Kazantzidis and K. Tourpali (2003) Climatological UV Maps over Europe from Ground-based and Satellite
Measurements. Technical report. Laboratory of Atmospheric Physics, Aristotle University of Thessaloniki, Thessaloniki.

42. Slaper, H. and T. Koskela (1997) Methodology of intercomparing spectral sky measurements, correcting for wavelength shifts, slit function differences and defining a spectral reference. In The Nordic Intercomparison of Ultraviolet and Total Ozone Instruments at Izana, October 1996, Izana (Edited by B. Kjeldstad, B. Johnson and T. Koskela), pp. 89-108. Meteorological publication no. 36. Finnish Meteorological Institute, Helsinki. 